\title{
O TEXTO AUTOBIOGRÁFICO EM SALA DE AULA DO ENSINO FUNDAMENTAL
}

\author{
THE AUTOBIOGRAPHICAL TEXT IN THE MIDDLE SCHOOL CLASSROOM
}

\author{
Flávia Cavalcante Rocha ${ }^{1}$, Aurea Suely Zavam ${ }^{1}$ \\ 1 Universidade Federal do Ceará (UFC), Fortaleza, CE, Brasil \\ flavia.prof@gmail.com; aurea.ufc@gmail.com
}

Recebido em 21 jul. 2018

Aceito em 5 ago. 2018

Resumo: Com este trabalho, objetivamos contribuir com o ensino e a aprendizagem da escrita por meio da produção de textos autobiográficos por alunos do 9o ano do Ensino Fundamental de uma escola pública de Fortaleza-CE. Concebemos uma sequência didática, baseada na proposta de Dolz, Noverraz e Schneuwly (2004), como recurso metodológico para verificar o desempenho dos alunos nos textos escritos assim como para comprovar a eficiência de tal procedimento como proposta de ensino. Desse modo, para desenvolver a competência dos alunos na produção de textos, sobretudo os escritos, seguimos, ainda, as orientações dos Parâmetros Curriculares Nacionais de Língua Portuguesa, e mais recentemente da Base Nacional Comum Curricular, que norteiam o trabalho com gêneros textuais em sala de aula e certificam que é necessário contemplar a diversidade de textos e gêneros, não apenas por sua relevância social, mas também porque textos pertencentes a diferentes gêneros são organizados de diferentes formas. Apresentamos, então, atividades direcionadas para o trabalho com o gênero autobiografia em sala de aula. Nessa perspectiva, trabalhamos a produção escrita, intencionando valorizar a identidade dos alunos e ressaltar a sua importância como indivíduos participativos e críticos na sociedade onde vivem. Em síntese, este trabalho se propõe a investir na melhoria das práticas de leitura e escrita e pode ser constituído como uma iniciativa pedagógica de aplicação do Modelo Ideológico de Letramento preconizado por Street(2014).

Palavras-chave: Ensino de língua portuguesa. Produção escrita. Sequência Didática. Autobiografia.

\begin{abstract}
With this work, we aim to contribute to the teaching and learning of writing through the production of autobiographical texts by students of the 9th grade of Middle School of a public school in Fortaleza-CE. We conceived a didactic sequence, based on the proposal of Dolz, Noverraz and Schneuwly (2004), as a methodological resource to verify students' performance in written texts as well as to prove the efficiency of such procedure as a teaching proposal. Thus, in order to develop students' competence in the production of texts, especially the written ones, we also follow the guidelines of the National Curriculum Parameters of the Portuguese Language, and more recently the National Curricular Common Base, which guide the work with textual genres in the classroom and certify that it is necessary to contemplate the diversity of texts and genres, not only because of their social relevance, but also because texts belonging to different genres are organized in different ways. We present, then, activities directed to the work with the autobiography genre in the classroom. From this perspective, we work on writing production, intending to value the students' identity and emphasize their importance as participatory and critical individuals in the society where they live. In summary, this work proposes to invest in the improvement of reading and writing practices and can be constituted as a pedagogical initiative of application of the Ideological Model of Literacy advocated by Street (2014).
\end{abstract}

Keywords: Portuguese language teaching. Written production. Didactic Sequence. Autobiography. 


\section{Introdução}

Não é novidade que grande parte dos alunos que sai da escola apresenta muitos problemas em relação à leitura e à escrita. Resultados de avaliações oficiais $\left(\right.$ ENEM e SAEB) ${ }^{1}$ têm comprovado essa afirmação: o Brasil ocupa, em relação a outros países da América Latina, uma das últimas posições no que se refere ao nível de conhecimento esperado de um aluno que conclui seus estudos no Ensino Fundamental e Médio, conforme o quadro comparativo dos resultados do Programa Internacional de Avaliação de Estudantes ${ }^{2}$ (PISA) dos anos de 2000, 2003, 2006, 2009 e 2012.

Além do PISA, que nos aponta indicadores do desempenho dos alunos no tocante à qualidade da sua escolarização, temos o Sistema de Avaliação da Educação Básica (SAEB) e o Exame Nacional do Ensino Médio (ENEM), os quais, por sua vez, nos apresentam resultados nacionais de desempenho dos estudantes em leitura e escrita, revelando essa realidade com dados preocupantes e visíveis de um insucesso nas áreas de conhecimento em questão.

Embora se verifique todo o esforço de professores, gestores e demais profissionais da Educação, o resultado do trabalho desenvolvido nas escolas ainda está aquém do que se espera, tendo em vista o objetivo de formar leitores e produtores proficientes de textos. Certamente, uma das causas desse fracasso escolar foi o entendimento equivocado, por parte dos profissionais da Educação, de uma forma geral, de que estudar a língua era estudar gramática. Essa era a visão acerca do trabalho com a língua na escola, uma visão restrita e reducionista. Hoje, entretanto, a perspectiva de trabalho é outra (NEVES, 2011).

Com o avanço dos estudos linguísticos e, consequentemente, entre nós, professores e estudiosos da língua, com o advento dos Parâmetros Curriculares Nacionais (PCN), e mais recentemente com a Base Nacional Comum Curricular (BNCC), o foco do trabalho foi modificado. O ponto central passa a ser o gênero, embora a filosofia de trabalho permaneça a mesma na maioria dos casos: continuase a trabalhar metalinguisticamente. Só que, agora, estuda-se sobre o gênero, sobre

1 Os resultados do ENEM e do SAEB podem ser consultados nos seguintes sites: <http://portal.inep.gov.br/web/enem/enem>; <http://portal.inep.gov.br/web/saeb/aneb-e-anresc>

2 O quadro comparativo dos indicadores do PISA pode ser consultado no site seguinte: <http://portal.inep.gov.br/internacional-novo-pisa-resultados> 
o texto - sem se deixar de estudar, também, sobre a gramática. Seu uso (do gênero, do texto e da gramática), entretanto, permanece, muitas vezes, à margem das aulas de língua. Essa postura ainda necessita ser revista por muitos professores e gestores (COSCARELLI, 2007).

Assim, para desenvolver a competência dos alunos na produção de textos, sobretudo os escritos, um dos focos deste trabalho, foram seguidas as orientações dos PCN de Língua Portuguesa e da BNCC, que norteiam o trabalho com gêneros textuais em sala de aula e certificam que é necessário contemplar em nossas atividades a diversidade de textos e gêneros, não apenas por sua relevância social, mas também porque textos pertencentes a diferentes gêneros são organizados de diferentes formas.

Nessa perspectiva, exploramos neste trabalho a escrita por meio da produção de textos autobiográficos redigidos por alunos do $9^{\circ}$ ano do Ensino Fundamental, numa tentativa de valorizar a identidade deles e de fazê-los perceber a sua importância como indivíduos participativos e críticos na sociedade em que vivem. Segundo Josso (2007), a autobiografia é considerada uma vertente da biografia em seu sentido amplo, podendo ser conhecida também por narrativa ou história de vida, classificada como uma oportunidade de refletir sobre diferentes tipos de expressão e representações de si. Além disso, o gênero autobiografia não vem sendo trabalhado, de forma satisfatória, nos livros didáticos, daí a necessidade do trabalho aqui desenvolvido com a utilização de materiais além do livro didático.

Desse modo, devido à pouca familiaridade dos discentes com o ensino por meio desse gênero e objetivando o domínio das competências e habilidades de escrita pelos alunos do Ensino Fundamental, aplicamos uma sequência didática, considerando-a como "um conjunto de atividades escolares organizadas, de maneira sistemática, em torno de um gênero textual oral ou escrito" (DOLZ; NOVERRAZ; SCHNEUWLY, 2004, p. 82). Seguimos também as considerações de Vieira (2005) no tocante à abordagem processual do ensino da escrita, valorizando mais as operações e habilidades necessárias à elaboração do texto do que o produto final obtido. Vieira (2005) afirma que a produção de um texto envolve distintos processos, subprocessos ou habilidades que podem servir para fins de ensino, uma vez que enfatizam os aspectos cognitivos implicados no ato de redigir. 
Para que os alunos pudessem conhecer e praticar os vários usos da linguagem em novas situações comunicativas e conceber o texto como processo, realizamos um conjunto de atividades sistematizadas, com objetivos definidos, relacionadas entre si, e grau de complexidade crescente. Oferecemos, portanto, no exercício dessas atividades, modelos; fornecemos pistas; indicamos caminhos; revisamos e colocamos em prática conceitos que culminaram com o desenvolvimento de diversas capacidades de linguagem. Para a análise dos textos produzidos,utilizamos um procedimento qualitativo, com proposta de intervenção, pois nos guiamos pela observação do desempenho e da capacidade dos alunos em desenvolver um tema, por meio de um texto escrito.

Esta pesquisa objetiva principalmente, entre outros propósitos, melhorar as práticas de leitura e escrita dos nossos alunos e constitui uma iniciativa pedagógica de aplicação do Modelo Ideológico de Letramento, preconizado por Brian V. Street (2014). Nesta obra, o autor (2014) propõe um modelo segundo o qual as práticas de leitura e escrita estão sempre inseridas não só em significados culturais, mas em posições ideológicas sobre o que conta como "letramento" e nas relações de poder a ele associadas. Street (2014) focaliza, portanto, a natureza social da leitura e da escrita e o caráter múltiplo das práticas letradas.

Para proceder ao relato da proposta, dividimos este texto em mais três partes, além desta parte introdutória. Nas três sessões seguintes, apresentamos os fundamentos teóricos de nosso estudo: o letramento, a concepção de gênero e especificamente a autobiografia, a escrita como processo e a proposta da sequência didática (SD). Em seguida, apresentamos o contexto, os participantes e os procedimentos da pesquisa. Na sessão posterior, apresentamos e discutimos os dados.

Por fim, apresentamos nossas considerações finais, com reflexões acerca dos resultados obtidos, da contribuição pretendida e da expectativa de futuras pesquisas.

\section{Por que falar em letramento?}

O conceito de letramento surgiu no Brasil aproximadamente em 1980. A criação desse termo está respaldada na necessidade de distinção entre processos em que 
haja somente a aprendizagem do sistema de escrita e processos em que o aprendiz é capaz de utilizar sua leitura e escrita para a realização de práticas sociais. Assim, a partir do momento em que se propôs o conceito de letramento, segundo Soares (2003), verificou-se a importância de reconhecer e nomear práticas sociais de leitura e de escrita mais avançadas e complexas que as práticas escolares do ler e do escrever.

Em 1990, na década posterior ao surgimento do termo "letramento", vários pesquisadores envolvidos com a aprendizagem e com o ensino da língua materna apontaram progressos em seus estudos, passando a compreender melhor a dimensão sociocultural da linguagem oral e escrita e o seu aprendizado. Os aprendizes passaram a ser encarados como sujeitos inseridos em práticas culturais diversas, e, como consequência, a leitura e a escrita foram reconhecidas como ferramentas culturais. Desse modo, as práticas de letramento superaram o conceito limitado que definia alfabetização como apropriação do código fonético. O letramento passou a ser considerado, portanto, como um processo educativo abrangente que permite ao aluno familiarizar-se com os diversos usos sociais da leitura e da escrita.

Street (2014) aborda o assunto como letramentos sociais por considerá-lo não apenas como a aquisição da linguagem escrita, mas como a aquisição de um vasto repertório de conhecimentos, entre os quais está a linguagem oral, que se apresenta estreitamente ligada à transmissão da cultura entre as gerações. Nesse sentido, defende a existência de múltiplos letramentos, não simplesmente um único voltado para a aquisição da variedade linguística de prestígio social. O autor também introduziu os conceitos de letramento autônomo e letramento ideológico, e o nosso trabalho está em consonância com esse segundo conceito, embasado numa ideologia muito mais ampla e social.

O Modelo Autônomo de Letramento estabelece uma forte separação entre oralidade e escrita, além de introduzir o processo de letramento através de enunciados isolados, que não levam os aprendizes à reflexão, tampouco abordam assuntos que façam parte de sua vida cotidiana. Já o Modelo Ideológico de Letramento considera a interação entre os participantes do evento comunicativo - o professor, o aluno e o texto - pois propicia diferentes modos de interagir com o texto escrito com base na variedade linguística, e não somente na variedade padrão, além 
de levar em conta o papel social do indivíduo na sociedade como determinante em suas práticas de letramento.

Desse modo, neste estudo, pretendemos exatamente o contrário do que preconiza o Modelo Autônomo de Letramento ainda utilizado, equivocadamente, pela maioria dos governos e agências alfabetizadoras, pois, ao aplicarmos nossa sequência didática em sala de aula, ainda que mais voltada para a escrita, trabalhamos a oralidade com os alunos participantes do processo através dos próprios relatos de vida deles, valorizando a realidade dos aprendizes e ressignificando nossa prática docente.

\section{A concepção de gênero textual e a autobiografia}

Como já salientamos, depois da publicação dos PCN (1998), o ensino de língua portuguesa passou a ser pautado pela abordagem dos gêneros textuais. Ainda que, no início, a discussão sobre os gêneros tenha se voltado basicamente para sua classificação e para o estudo de suas formas, a constante divulgação dos estudos de Bakhtin (1895-1975), sem dúvida, vem contribuindo significativamente para uma mudança de perspectiva e, assim, o aspecto sociointeracional presente na atividade de produção de textos passou a ser considerado.

Contrário a uma concepção de língua pautada no código, somente no valor normativo, Bakhtin (2000) ressalta o valor plástico dos gêneros, sua capacidade de combinação nas mais diversas situações de uso. Para o linguista russo, um gênero é escolhido tendo em vista a esfera, as necessidades da temática, o conjunto das práticas e a vontade enunciativa ou a intenção do locutor.

O autor (2000) assegura que a riqueza e a variedade dos gêneros não têm fim, pois a variedade virtual da atividade humana não se esgota e cada esfera dessa atividade engloba um repertório dos gêneros do discurso que se diferencia e se amplia à medida que a própria esfera se desenvolve e se torna mais complexa. Desse modo, os gêneros são constituídos historicamente a partir de novas situações de interação verbal da vida social. Embora muitos deles sejam de conhecimento do senso comum, não estão cristalizados, de forma que se modificam a depender das novas demandas enunciativas que apareçam. 
Acrescenta Bakhtin (2000) às suas considerações que os gêneros textuais são enunciados (orais e escritos), concretos e únicos, proferidos pelos participantes de uma ou outra esfera da atividade humana na qual o uso da língua é efetuado. Afirma ainda que, através dos tempos, no quadro das atividades sociais, foram e são produzidas determinadas formas comunicativas que, estabilizando-se de modo mais ou menos forte, constituem os gêneros textuais. A diferenciação das esferas da atividade teria levado, e ainda leva, a uma constante diferenciação dos gêneros de textos próprios de cada uma dessas esferas.

Para Bakhtin (2000), gêneros textuais são, portanto, tipos textuais, relativamente estáveis, de natureza socioideológica e discursiva, que estão relacionados a situações da comunicação social. Assim, constatamos que a composição do gênero discursivo extrapola o linguístico, visto que também apresenta uma dimensão social por estar vinculado à situação social de interação, tendo cada gênero sua própria finalidade discursiva e sua própria concepção de autor e destinatário.

Baseados em Bakhtin (2000), Dolz, Noverraz e Schneuwly (2004) veem o gênero como um instrumento, uma ferramenta imprescindível numa comunicação (falada e escrita), com uma situação definida por uma intenção comunicativa, num determinado local e com destinatários. Na situação comunicativa, há um sujeito, o locutor-enunciador, que age discursivamente por uma série de parâmetros, com o auxílio, portanto, de um instrumento que aqui é um gênero, isto é, uma forma de linguagem, que permite, a um só tempo, a produção e a compreensão dos textos. Os autores defendem que os gêneros, como instrumentos, podem ser trabalhados na sala de aula por meio de uma sequência didática, cujo objetivo é "ajudar o aluno a dominar um gênero de texto, permitindo-Ihe, assim, escrever ou falar de uma maneira mais adequada numa situação de comunicação". Nossa escolha em desenvolver o nosso trabalho embasados numa sequência didática repousa justamente nessa proposta. E para tal, elegemos a autobiografia.

Ao narrar acontecimentos sobre sua vida, o aluno aciona o que está em sua memória e, por meio dela, evoca e seleciona alguns eventos, escolhe o que e como dizer. Escrever a autobiografia pode ser uma boa oportunidade para retomar, refletir e analisar sua trajetória. Temos conhecimento de que a vida nãoé escrita, mas a 
escrita sobre a vida possibilita apropriar-se dela e aprender com ela de maneira singular. A narração autobiográfica, portanto, apresenta-se como uma oportunidade para remexer o baú da memória, e as lembranças podem ser resgatadas aos poucos pelos alunos, o que é bastante motivador para eles.

Nessa linha de pensamento, Thomson (1997), ao afirmar que recordar está intimamente ligado à identidade pessoal que construímos ao longo da nossa vida na interação com outras pessoas e com nossa própria vivência, estabelece uma ligação entre memória e identidade e esclarece que:

O processo de recordar é uma das principais formas de nos identificarmos quando narramos uma história. Ao narrar uma história, identificamos o que pensamos que éramos no passado, quem pensamos que somos no presente e o que gostaríamos de ser. As histórias que relembramos não são representações exatas de nosso passado, mas trazem aspectos desse passado e os moldam para que se ajustem às nossas identidades e aspirações atuais. Assim, podemos dizer que nossa identidade molda nossas reminiscências; quem acreditamos que somos no momento e o que queremos ser afetam o que julgamos ter sido. Reminiscências são passados importantes que compomos para dar um sentido mais satisfatório à nossa vida, à medida que o tempo passa, e para que exista maior consonância entre identidades passadas e presentes (THOMSON, 1997, p. $57)$.

Acrescenta ainda o referido autor que "a experiência nunca termina, é constantemente relembrada e retrabalhada" (THOMSON, 1997, p. 57) no decorrer da vida, em uma tentativa de compor uma memória e uma identidade com as quais possamos conviver.

Cardoso e Maia-Vasconcelos (2009) explicaram a autobiografia tomando por base a Linguística Textual, usando as noções de gênero e tipo de texto para explicitar as escritas autobiográficas. Esse tipo textual, chamado pelas autoras tipo narrativo, vai além das categorias tratadas por Barthes (1973) denominadas pelo autor de níveis da narrativa. As histórias de vida e as narrativas autobiográficas formam uma classe narrativa que abrange as diversas formas de manifestações narrativas cunhadas na emotividade - relação com o produtor do texto - e na realidade dos fatos, aspectos relevantes na construção discursiva.

Ainda segundo as autoras (2009) mencionadas, contar a própria história é um exercício de autoconsciência, de distanciamento que faz com que o narrador, numa espécie de reflexão interna, seja expectador de si mesmo: um eu que deseja contar 
sua história pessoal, que cria e ao mesmo tempo observa, dialoga e intervém no processo de criação.

Desse modo, ainda segundo as autoras, em termos estruturais, a construção da narrativa autobiográfica acontece da seguinte forma: existe um autor-narradorescritor, um ser que possui experiência no mundo das práticas sociais, que narra, por meio de um processo de escrita, essa experiência do mundo para um leitor-real, que recebe e compartilha a verossimilhança dos fatos e tenta estabelecer uma comparação com os fatos vividos em sua vida. A narratologia, então, não busca conhecer provas do que diz o sujeito e toma o relato como verdadeiro. $O$ analista não remonta para além da história ou se pronuncia sobre os fatos postos no relato. A descoberta do narrador é aceita como real. O centro do interesse é a compreensão das estratégias de construção do discurso autobiográfico, como relato de vida, as escolhas, os caminhos buscados pelo autor de seu texto no momento da criação e da escuta.

Baccin (2008), por sua vez, apresentou um modelo didático de gênero e sequência didática utilizando-se da autobiografia. Com isso, desenvolveu um trabalho pautado na teoria da enunciação e dos gêneros discursivos (BAKHTIN, 2000) e dos gêneros textuais (BRONCKART, 2003), oferecendo, portanto, uma significativa contribuição no sentido de possibilitar lançarmos vários olhares para o texto, compreendendo-o quanto a sua situação de produção, a sua função social e quanto às marcas linguísticas que o constituem. Esse viés apresentado pela autora nos rendeu algumas contribuições significativas para a nossa proposta, uma vez que nos utilizamos das suas considerações como sugestões de análise do gênero autobiografia, apontando e confirmando algumas marcas próprias do gênero em questão e que o definem como tal. Para os objetivos de nosso estudo, entretanto, fizemos adaptações ao quadro proposto pela autora (BACCIN, 2008, p.27-28) e assim chegamos ao que mostramos a seguir.

Quadro 1 - As principais marcas do gênero textual autobiografia: uma proposta de análise

\begin{tabular}{|l|l|l|}
\hline \multicolumn{3}{|c|}{ AUTOBIOGRAFIA } \\
\hline \multicolumn{1}{|c|}{ Contexto de produção } & \multicolumn{1}{|c|}{ Plano discursivo } & \multicolumn{1}{|c|}{ Marcas linguísticas } \\
\hline $\begin{array}{l}\text { • Quem é o protagonista da } \\
\text { história? É o próprio autor? O } \\
\text { texto está em primeira } \\
\text { pessoa? }\end{array}$ & $\begin{array}{l}\text { do autor? O autor se mostra } \\
\text { no texto? }\end{array}$ & $\begin{array}{l}\text { pessoais e possessivos na } \\
\text { pesimeira pessoa? } \\
\text { p Verifica-se o predomínio }\end{array}$ \\
\hline
\end{tabular}




\begin{tabular}{|c|c|c|}
\hline $\begin{array}{l}\text { - Os textos mostram os } \\
\text { principais episódios da vida do } \\
\text { autor, de forma cronológica, } \\
\text { com ênfase maior a certos } \\
\text { acontecimentos? } \\
\text { - A quem se destina o texto, } \\
\text { ou seja, quem é o seu possível } \\
\text { leitor? Para quem ele } \\
\text { escreverá? } \\
\text { - Com que objetivo ele } \\
\text { escreverá? } \\
\text { - Em que formato ele deverá } \\
\text { escrever, isto é, em que } \\
\text { gênero? }\end{array}$ & $\begin{array}{l}\text { - Em relação ao tipo de } \\
\text { discurso, predomina o } \\
\text { relato? Então são textos } \\
\text { predominantemente } \\
\text { narrativos? } \\
\text { - No plano global, como } \\
\text { se estrutura o texto? São } \\
\text { textos longos ou curtos? } \\
\text { Relatam minuciosamente a } \\
\text { história do autor ou relatam } \\
\text { passagens da vida dele de } \\
\text { forma mais objetiva? }\end{array}$ & $\begin{array}{l}\text { de verbos no } \text { Pretérito } \\
\text { Perfeito e no Pretérito } \\
\text { Imperfeito? E, outras } \\
\text { vezes, no Presente? } \\
\text { - Existem marcadores } \\
\text { temporais (datas, anos, } \\
\text { expressões de tempo)? } \\
\text { - Existem marcadores } \\
\text { espaciais, ou seja, de } \\
\text { lugar? }\end{array}$ \\
\hline
\end{tabular}

Fonte: Adaptação das proposições de Baccin (2008).

\section{Escrita e sequência didática}

No decorrer de sua obra, Vieira (2005) apresenta ao leitor a abordagem considerada mais significativa para o ensino da escrita nas três últimas décadas - a abordagem processual. Nessa perspectiva, valorizam-se mais as operações e habilidades necessárias à elaboração do texto do que o produto final obtido, o que é exatamente o contrário do que ainda se observa na prática escolar, numa visão equivocada do processo de escrever. Acrescenta ainda que, para ensinar a redigir, é preciso, acima de tudo, que o professor tenha consciência de que a escrita é uma atividade comunicativa e que desempenha funções definidas e cada vez mais diversificadas no dia a dia de uma sociedade letrada.

Segundo Vieira (2005), pelo menos quatro aspectos devem ser levados em consideração na hora de um bom redator compor o seu texto, os quais podem ser assim enumerados: planejamento, releitura durante a elaboração do texto, revisão e consciência da audiência. $O$ ato de escrever ou redigir não pode ser descontextualizado, devendo apresentar claramente um propósito comunicativo e um leitor definido.

A partir das considerações feitas pela autora, compreendemos e constatamos a necessidade de mudanças nos critérios de avaliação das produções textuais dos alunos do Ensino Fundamental. Os textos não podem ser avaliados simplesmente considerando os aspectos ortográficos e gramaticais, os quais representam apenas uma parte do processo e são superficiais, mas sim na perspectiva de valorização da 
construção do texto, voltando a nossa atenção para aspectos como a seleção e organização das ideias, a manutenção do assunto, a progressão temática e o manejo de recursos de coesão.

A autora afirma que a produção de um texto envolve distintos processos, subprocessos ou habilidades, que podem ser isolados para fins de ensino e aprendizagem, embora não costumem ser ensinados de forma explícita. Essa visão da escrita, conhecida como abordagem processual ou componencial, ressalta ou prioriza os aspectos cognitivos envolvidos no ato de redigir.

Visando cobrir as etapas do processo da escrita, decidimos trabalhar com a sequência didática (SD). Assim, focalizando o gênero autobiografia, voltamos nosso olhar para a análise dos textos que seriam produzidos para então investir na habilidade de produção de textos dos alunos do $9^{\circ}$ ano do Ensino Fundamental.

Dolz, Noverraz e Schneuwly (2004, p. 83) defendem que a finalidade de trabalhar com sequência didática é "ajudar o aluno a dominar melhor um gênero de texto, permitindo-Ihe, assim, escrever ou falar de uma maneira mais adequada numa situação de comunicação". Os autores definem sequência didática como um "conjunto de atividades escolares organizadas, de maneira sistemática, em torno de um gênero textual oral ou escrito" (p. 82) e apresentam a estrutura de base de uma sequência didática que pode ser representada pela seguinte figura:

Figura 1: Esquema da sequência didática

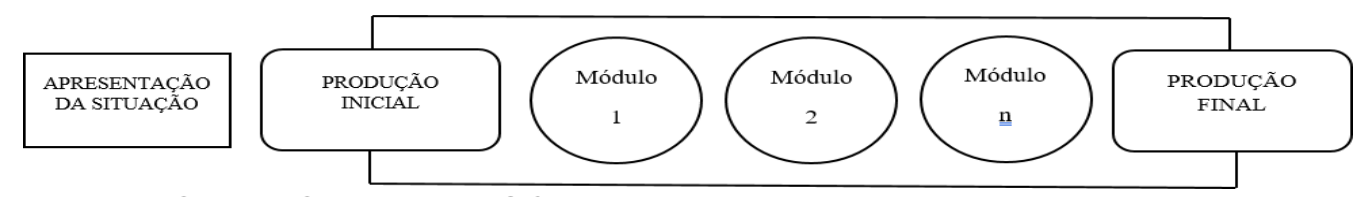

Fonte: DOLZ; NOVERRAZ; SCHNEUWLY, 2004, p.83.

O primeiro passo é apresentar a situação de comunicação. Nesta etapa, descreve-se detalhadamente a tarefa a ser desenvolvida e a modalidade utilizada pelo aluno, que corresponde ao gênero utilizado; logo após, os conteúdos que serão trabalhados devem ter relação com o gênero, o qual deve ser apresentado aos alunos e com eles discutido os aspectos da organização do gênero em questão.

Em seguida, é proposta a primeira produção textual, que pode ser realizada coletiva ou individualmente. Nesta etapa, o professor avalia as capacidades já adquiridas e ajusta as atividades e os exercícios previstos na sequência às 
possibilidades e dificuldades reais da turma. Além disso, esta atividade define as capacidades que os alunos devem desenvolver para melhor dominar o gênero de texto em questão.

Na etapa dos módulos, os problemas que foram detectados na produção inicial são trabalhados para serem superados por meio de instrumentos necessários a essa superação. Estes módulos vão do complexo ao mais simples, para finalizar com o mais complexo, que é a produção final.

Na última etapa, a produção final, o professor realiza uma avaliação somativa e o aluno reconhece o que construiu, por que o fez e de que forma, aprendendo a monitorar suas ações e selecionando o gênero de acordo com a situação em que pode ser usado. Nesta avaliação, consideram-se os progressos e as limitações ainda existentes nas produções escritas do aluno, para haver os redirecionamentos necessários nas próximas ações e atingir a eficiência desejada a partir desta percepção.

Acreditamos que, a partir do desenvolvimento de uma sequência didática, seja possível ensinar a escrever textos e a exprimir-se oralmente em situações públicas escolares e extraescolares. Uma proposta assim tem sentido quando se inscreve num ambiente escolar, no qual múltiplas ocasiões são oferecidas aos alunos, sem que cada produção se transforme, necessariamente, num objeto de ensino sistemático. Criar contextos de produção precisos, efetuar atividades ou exercícios múltiplos e variados: é isto que permitirá aos alunos apropriarem-se das noções, das técnicas e dos instrumentos necessários ao desenvolvimento de suas capacidades de expressão oral e escrita, em situações de comunicação diversas.

\section{A metodologia do trabalho}

Apresentamos, nas seções seguintes, a construção e o desenvolvimento da nossa abordagem, ou seja, a metodologia que adotamos para atingirmos os objetivos propostos.

\subsection{O contexto da pesquisa e os sujeitos}


Nossa proposta de ensino foi realizada em uma turma de $9^{\circ}$ ano de uma escola de ensino Fundamental da rede pública de Fortaleza, reconhecida pelo engajamento com as questões e os projetos sociais desenvolvidos.

Tínhamos, ao todo, 26 estudantes frequentando a escola, com idade entre 14 e 20 anos (idade do aluno mais velho da turma), sendo 9 (nove) meninas e 17 (dezessete) meninos, os quais normalmente são moradores do entorno da escola. Levando em consideração a faixa etária e o relato dos próprios estudantes, concluímos que a maioria deles somente estuda e mora com pais e/ou avós.

Os estudantes desenvolveram as atividades propostas dentro de uma sequência didática, em cinco módulos, as quais foram realizadas em 8 (oito) encontros, de 2 (duas) horas-aula cada, no período do segundo bimestre do ano letivo de 2016.

\subsection{Materiais}

O material analisado abrange os textos produzidos pelos estudantes participantes de todas as atividades da sequência didática desenvolvida. Esses textos produzidos foram denominados de:

a) produção inicial - que foi realizada no segundo encontro, após a apresentação da situação, porém antes mesmo da proposição das atividades de leitura e escrita e do estudo detalhado do gênero nos módulos;

b) produção final - que foi desenvolvida após o último módulo da sequência didática, momento no qual se acredita que os alunos tenham aperfeiçoado a competência comunicativa escrita deles e se apropriado do gênero trabalhado, cumprindo, desse modo, o propósito comunicativo da proposta de produção.

No momento da realização da produção inicial, fizemos cópias de uma proposta de produção de uma autobiografia e utilizamos com os alunos, que se sentiram motivados a produzir, visto que a referida proposta estava de acordo com a realidade deles. Fizemos, em seguida, uma rápida revisão dos aspectos constitutivos do gênero para depois solicitar a produção escrita individual, em folha padrão criada pela gestão da escola. 
Durante a aplicação dos módulos da sequência didática, utilizamos as cópias dos textos e das atividades elaboradas, visto que não constam no livro didático, as quais foram distribuídas de forma individual ou em duplas.

\subsection{Procedimentos}

Realizamos oito encontros de duas horas-aula de cinquenta minutos cada. No primeiro momento, foi apresentada nossa proposta de trabalho sobre a sequência didática. Depois expusemos as explicações básicas sobre o gênero autobiografia, com a leitura de alguns textos autobiográficos, para aproximar os alunos do gênero em que deveriam escrever. Após esse primeiro contato formal com o gênero em questão, os alunos produziram um texto condizente com a proposta sugerida, mas, a princípio, concebida como a produção da autobiografia deles. Esses textos constituíram, assim, a nossa produção inicial. Os alunos foram observados no instante da produção de seus textos, com o propósito de avaliarmos o processo de planejamento de escrita. E o que ficou bem claro foi o fato de poucos alunos terem feito rascunho; escreveram diretamente na folha de produção recebida, evidenciando pouca familiaridade com a prática de um planejamento de escrita.

O próximo passo foi analisarmos os textos iniciais de cada aluno, levantando as principais dificuldades relacionadas ao gênero desenvolvido. Em seguida, construímos as atividades da sequência didática, a qual foi adequada à realidade da turma e dividida em módulos, com o objetivo de superar as dificuldades identificadas.

No desenvolvimento dos módulos, cada um com o seu objetivo específico e com duração de 2 (duas) horas-aula de 50 (cinquenta) minutos, foram realizadas atividades diversas, como: leitura compartilhada, com a finalidade de incentivar o aluno à leitura e de exercitar estratégias para desenvolvê-la; exercícios de interpretação e de produção de textos escritos, conduzidos pelo professor, sobre o gênero autobiografia; atividades de retextualização para melhor assimilar as características do gênero trabalhado. Nesse momento, também foram debatidas, em grupo, as principais dificuldades identificadas na produção inicial. 
Em determinados módulos, os estudantes fizeram atividades de revisão e reescrita das suas autobiografias, levando em consideração a estrutura do gênero e também o seu conteúdo, mediados pelo professor. Desse modo, produziram o texto final, utilizando os conhecimentos construídos e compartilhados durante os módulos.

Os textos finais, denominados de produção final, foram também analisados em relação à apropriação do gênero estudado e de sua estrutura de composição, com o intuito de avaliar se os discentes conseguiram desenvolvê-la adequadamente e se o

uso da sequência didática propiciou a competência textual dos estudantes, de acordo com o que foi identificado em suas produções iniciais.

Após o desenvolvimento dessas etapas, com os textos já analisados e reescritos, organizamos um livro, intitulado pelos próprios autores como "Autobiografias: páginas da vida", com as produções textuais dos alunos para socializar o trabalho deles com a comunidade escolar e suas respectivas famílias na festa de conclusão de curso, no final do ano letivo, quando cada um entregou um exemplar do material à família.

Fizemos também a sugestão de publicação dos textos finais dos alunos, que foram digitados por eles próprios no laboratório de informática da escola, no site do Museu da Pessoa, no link seguinte: http://www.museudapessoa.net/pt/home. O referido site é constituído de histórias de vida. Em seguida, mostramos aos alunos um breve histórico sobre o Museu da Pessoa, explicamos o que vem a ser, um pouco da história dele, quando surgiu, qual o propósito da publicação de textos nesse site. Tudo isso com a finalidade de motivá-los a fazer o envio das suas histórias de vida também e de viabilizar a circulação do gênero na sociedade.

\section{Analisando os resultados}

A partir da nossa experiência em sala de aula, constatamos que ocorreu um comprometimento ou engajamento significativo por parte dos alunos na frequência aos encontros semanais e, portanto, na participação no processo da aplicação e do desenvolvimento da sequência didática proposta. Esse fato nos motivou também a continuar empolgados com a pesquisa realizada, o que significa muito em um 
trabalho dessa natureza, que exige do professor-pesquisador um empenho enorme e uma dedicação considerável.

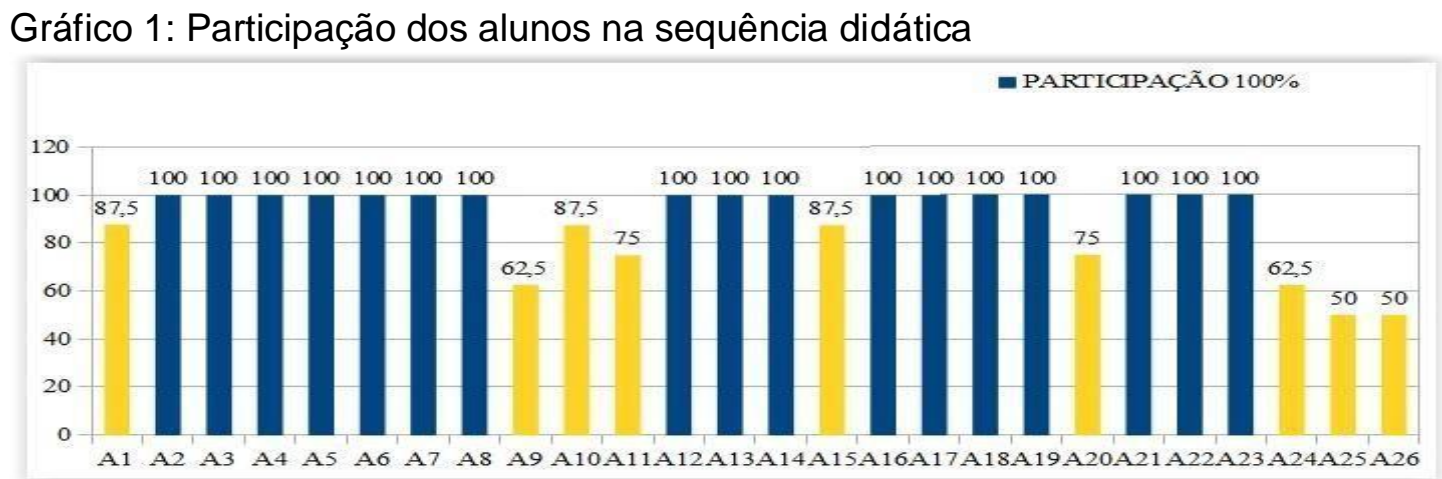

Fonte: Elaboração própria.

Ao todo, 26 (vinte e seis) alunos participaram das atividades sugeridas nos oito encontros realizados. Porém, selecionamos somente aqueles que participaram de todos os encontros, que foram 17 (dezessete). Desse modo, 34 (trinta e quatro) produções foram analisadas: 2 (duas) de cada um dos participantes ${ }^{3}$. Os alunos foram identificados como A1 a A26 (Aluno $\mathrm{n}^{\circ} 1$ a aluno $\mathrm{n}^{\circ}$ 26). A análise que empreendemos foi embasada nas proposições de Baccin (2008). Assim focalizamos as marcas do gênero autobiografia.

Por questões de atendimento aos propósitos e limitações de espaço deste artigo, trazemos aqui apenas a produção de um aluno com o objetivo de termos uma ideia do desempenho dos alunos.

Produção inicial (participante A2)

3 Todas as produções finais, mesmo aquelas dos alunos que não participaram de todos os encontros da sequência didática desenvolvida, encontram-se no livro organizado por nós e entregue aos estudantes dessa turma de 9o ano. Tomamos essa iniciativa por considerarmos importante a valorização do trabalho de todos os alunos. 


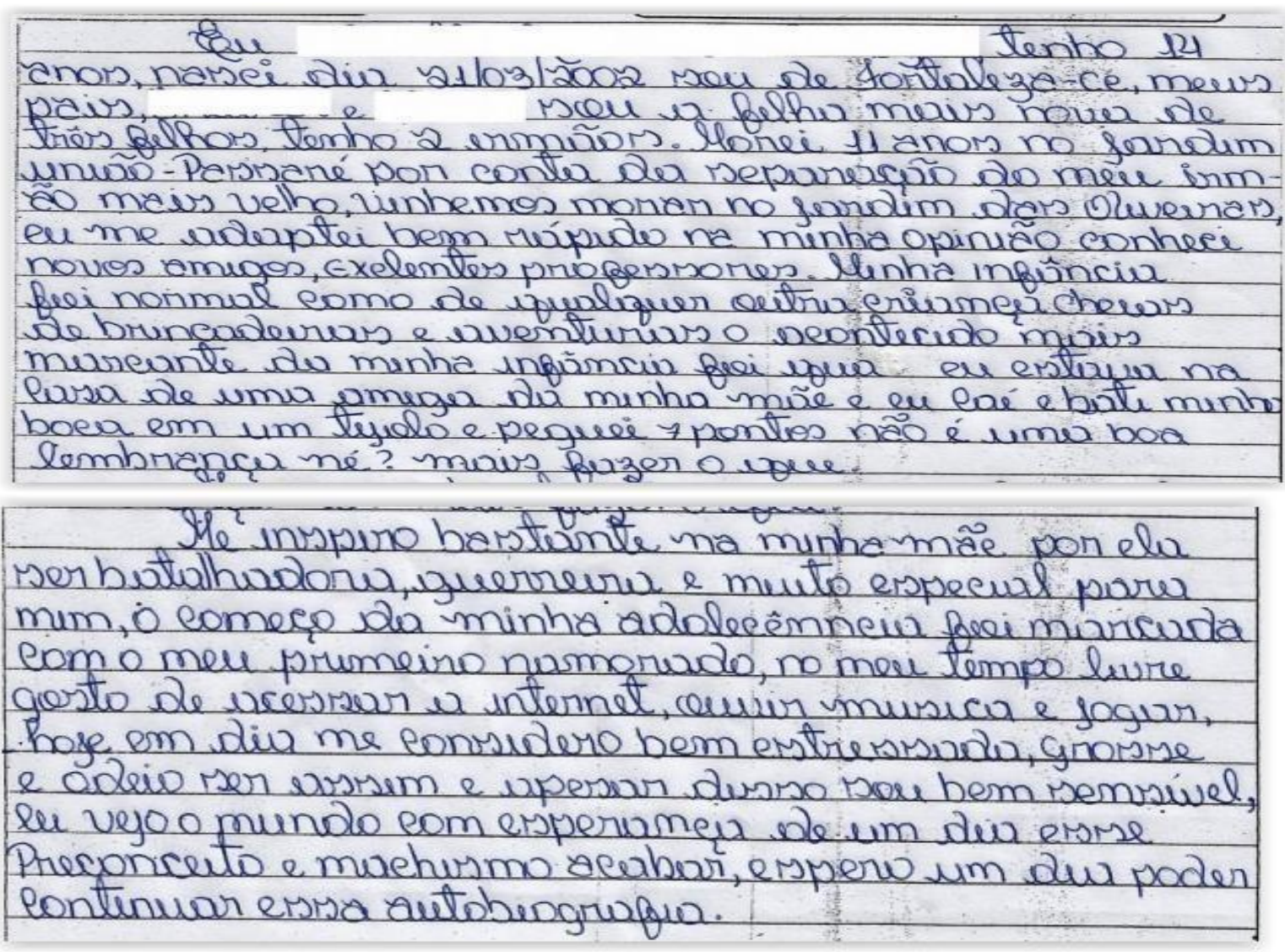

Produção final (participante A2)

Eu, A2, tenho 14 anos, nasci no dia 21/03/2002, em Fortaleza-CE. Meus pais são e , sou a filha mais nova de três filhos. Morei 11 anos no Jardim União, Passaré, por conta de um acidente que aconteceu com meu irmão mais velho, que logo depois se separou, e viemos morar no Jardim das Oliveiras.

Eu me adaptei bem rápido na minha opinião, conheci novos amigos e excelentes professores. Minha infância foi normal, como de qualquer outra criança, cheia de brincadeiras e aventuras. O acontecimento mais marcante da minha infância foi quando eu estava na casa de uma amiga da minha mãe e caí e bati minha boca em um tijolo. Levei 7 pontos. Não é uma boa lembrança, né?! Mas o que eu podia fazer?

Minha mãe é uma boa inspiração para mim, ela é trabalhadora, guerreira e muito especial. O começo da minha adolescência foi marcado pelo meu primeiro namorado. No meu tempo livre, gosto de acessar a internet, ouvir músicas e jogar. Eu sou uma pessoa bem estressada, grossa, mas, apesar de ser assim, também sou sensível, eu vejo o mundo com a esperança de um dia esse preconceito e essa 
diferença que as pessoas criam entre todos nós acabarem. Espero também um dia poder continuar essa autobiografia.

O aluno $\mathrm{A} 2$, em sua primeira produção, de um modo geral, atendeu às expectativas do gênero proposto, a autobiografia, em relação ao contexto de produção, ao plano discursivo e no tocante às marcas linguísticas características desse gênero. Verificamos, porém, algumas inadequações vocabulares; falhas ortográficas de acentuação e de pontuação; uma colocação pronominal indevida no início do último parágrafo; um problema de concordância nominal no segundo parágrafo, "Minha infância foi normal como de qualquer outra criança cheias" (grifo nosso); uma falha de paragrafação, por ter escrito o seu texto em dois parágrafos apenas, comprometendo a continuidade do texto; enfim, observamos também falhas de estruturação textual no final da produção da participante em análise.

Essas falhas não foram o eixo central de abordagem das atividades da nossa sequência didática, porém tentamos solucioná-las nos feedbacks coletivo e colaborativo, mais precisamente no módulo 5, que foi reservado para esse fim. Desse modo, em partes, o aluno A2 conseguiu perceber esses problemas e fazer as devidas adequações na sua produção final. Assim, verificamos alguns progressos nesses aspectos analisados.

Em relação à sua produção final, o participante $A 2$ realizou novas construções textuais a fim de melhor organizar suas ideias e de permitir uma maior compreensão do seu texto pelo leitor. Para comprovar essa nova realidade, selecionamos o primeiro e o último parágrafos para realizar a análise, pois representam melhor os progressos constatados nessa produção escrita.

Em sequência, ressaltamos que a autora e protagonista da história apresentou um forte grau de implicação na sua escrita, quando revelou suas características psicológicas, mesmo aquelas mais negativas segundo ela própria, de modo tão claro e direto no último parágrafo, embora tenha deixado explícito que nutria uma esperança, que ela própria não conseguiu explicar claramente, sobre o preconceito, não se sabe ao certo de que natureza, que as pessoas insistem em carregar e que ela gostaria que acabasse. Além disso, demonstrou grande satisfação ao se referir à mãe como guerreira e batalhadora, considerando-a como sua inspiração para viver. 
Mostrou-se também esperançosa em terminar essa autobiografia um dia, o que representou um desejo latente de socializar suas vivências com outras pessoas no futuro também.

A estudante A2 utilizou a primeira pessoa para relatar fatos e acontecimentos de sua história de vida em ordem cronológica, sendo, portanto, a protagonista e o própria autora das suas experiências; apresentou sentimentos e emoções da sua história, com ênfase em alguns momentos vividos; escreveu predominantemente no pretérito perfeito e imperfeito, os tempos característicos do gênero em questão, com algumas passagens no presente, para tratar de fatos atuais; fez um relato através de um texto curto, breve e conciso, desenvolvendo, assim, uma narrativa. Fez uso de pronomes pessoais e possessivos em primeira pessoa, de marcadores temporais e espaciais, redigindo, desse modo, uma autobiografia para compor uma coletânea de textos com as histórias de vida registradas.

\section{Considerações Finais}

Corroborando e reafirmando os nossos resultados, constatamos que a análise dos textos dos alunos participantes da nossa SD revelou que o trabalho com o gênero autobiografia para se alcançar os nossos objetivos de avanço nas produções escritas dos estudantes foi realmente produtivo. Os aprendizes se mostraram dispostos a relatar os fatos vividos e a socializar com o possível leitor e com os colegas de sala, não demonstrando resistência no ato da escrita e da realização das atividades propostas, embora o que temos o costume de verificar nessas turmas de Ensino Fundamental II seja exatamente o contrário, ou seja, alunos resistentes e desinteressados no momento da produção escrita.

Enfatizamos ainda que os estudantes se sentiram mais valorizados quando perceberam os progressos alcançados após as análises dos seus textos e também mais motivados quando receberam a notícia de que teriam as suas autobiografias reunidas em um livro que seria entregue aos seus familiares no encerramento deste ano letivo. Desse modo, as famílias desses alunos poderiam conhecer as experiências de vida dos seus filhos a partir do próprio relato deles e também 
teríamos o registro do trabalho desenvolvido na escola, servindo para futuras pesquisas e consultas.

Finalmente, diante dos resultados favoráveis apresentados nos textos dos alunos envolvidos neste projeto, percebemos a importância de se trabalhar, com uma maior frequência, as sequências didáticas no Ensino Fundamental, devido não só à boa aceitação pelos alunos como também à constatação das suas reais necessidades em relação à competência escrita e ao desenvolvimento das suas capacidades de linguagem, dando continuidade às pesquisas e às discussões sobre o tema e ficando como sugestão para futuros pesquisadores que realizarem um trabalho com a autobiografia de estudantes que avancem nos conhecimentos que não pudemos abranger.

Com este artigo, pretendemos, pois, contribuir para o trabalho do professor de Língua Portuguesa, com o propósito de que ele continue propiciando a motivação de seus alunos, ou seja, estimulando-os e instigando-os no interesse pelos textos de diferentes gêneros. Além disso, almejamos ainda favorecer a realização, por parte do professor, de atividades diferentes, que estimulem a leitura e a produção de textos, além daquelas já propostas pelo livro didático, para tornar o discente um leitor crítico e um cidadão consciente do seu papel na sociedade.

\section{Referências}

BACCIN, E.J. Modelo didático de gênero e sequência didática: gênero textual autobiografia. Programa de Desenvolvimento Educacional 2008/2009-PDE. Secretaria de Estado da Educação do Paraná/Secretaria de Tecnologia e Desenvolvimento. Dois Vizinhos-PR: 2008. Disponível em:

<http://www.diaadiaeducacao.pr.gov.br/portals/pde/arquivos/2000-6.pdf>. Acesso em: 04 out. 2016.

BARTHES, R. Análise estrutural da narrativa. Petrópolis: Vozes, 1973.

BAKHTIN, M. Estética da criação verbal. 3. ed. São Paulo: Martins Fontes, 2000.

BRASIL. Ministério da Educação e do Desporto. Secretaria de Educação Fundamental. Parâmetros Curriculares Nacionais - PCN - Terceiro e quarto ciclos do Ensino Fundamental - Língua Portuguesa. Brasília: MEC/SEF, 1998. . Ministério da Educação. Secretaria da Educação Básica. Base Nacional 
Comum Curricular. Brasília, DF, 2016. Disponível em:

<http://basenacionalcomum.mec.gov.br/\#/site/inicio>. Acesso em: dez. 2017.

BRONCKART, J. P. Gêneros textuais, tipos de discursos e operações psicolingüísticas. Revista de Estudos da Linguagem,Belo Horizonte, v. 11,n. 1, p. 49-69, 2003.

CARDOSO, M. N. F.; MAIA-VASCONCELOS, S. M. F. Novas fronteiras linguísticas: um estudo sobre o gênero autobiográfico. Eutomia - Revista Online de Literatura e Linguística da UFPE, v. 2, p. 653-664, 2009.

COSCARELLI. C. V. Gêneros textuais na escola. Veredas online, v. 2, p. 78-86, 2007. Disponível em: <https://www.ufjf.br/revistaveredas/files/2009/12/artigo051.pdf> Acesso em: 14 set. 2016.

DOLZ, J.; NOVERRAZ, M.; SCHNEUWLY, B. Sequências didáticas para o oral e a escrita: apresentação de um procedimento. In: Gêneros orais e escritos na escola. Campinas, SP: Mercado de Letras, 2004. p. 95-128.

JOSSO, M.-C. A transformação de si a partir da narração de histórias de vida. Revistas Eletrônicas da PUCRS: Porto Alegre/RS, ano XXX, n. 3 (63), p. 413-438, set./dez. 2007. Disponível em:

$<$ http://caioba.pucrs.br/face/ojs/index.php/faced/article/viewFile/274/2088>. Acesso em: 12 out. 2017.

MUSEU DA PESSOA. Disponível em: <http://www.museudapessoa.net/pt/home>. Acesso em: 08 jul. 2017.

NEVES, M. H. M. Gramática: reflexões sobre um percurso de elaboração de manuais. Revista da ABRALIN, v. eletrônico, n. especial, p. 33-51. 1ª parte, 2011.

SOARES, M. Letramento e alfabetização: as muitas facetas. Belo Horizonte: Universidade Federal de Minas Gerais, Centro de Alfabetização, Leitura e Escrita, 2003.

STREET, B. Letramentos sociais: abordagens críticas do levantamento no desenvolvimento, na etnografia e na educação. São Paulo: Parábola Editorial, 2014.

THOMSON, A. Recompondo a memória: questões sobre a relação entre a história oral e as memórias. Projeto História, Ética e História Oral. São Paulo, 1997.

VIEIRA,I. L. Escrita para que te quero? Fortaleza: Edições Demócrito RochaUECE, 2005. 


\section{Sobre as autoras}

\section{Flávia Cavalcante Rocha}

Mestre em Letras pela Universidade Federal do Ceará. Graduada em Letras pela Universidade Federal do Ceará. Professora de Língua Portuguesa na rede pública de Fortaleza. Tem experiência no ensino de produção textual e na correção de redação de pré-vestibulares.

\section{Aurea Suely Zavam}

Pós-doutorado em Estudos Linguísticos pela Universidade Federal de Minas Gerais. Doutora e mestre em Linguística pela Universidade Federal do Ceará. Graduada em Letras pela Universidade Estadual do Rio de Janeiro. Foi professora de língua portuguesa no ensino fundamental e médio na rede particular de ensino. Atualmente é professora da Unidade de Prática de Ensino da Universidade Federal do Ceará. É membro do Conselho Titular do Grupo de Estudos Linguísticos do Nordeste. 